\section{Chipping bucket - a new and feasible approach for fragmentation of oil palm trunk}

\author{
P. Preethi ${ }^{1}$, T. V. Singh ${ }^{2, *}$, M. V. Prasad $^{3}$, \\ D. Ramajayam ${ }^{4}$, N. V. Ganesh ${ }^{3}$, R. K. Mathur ${ }^{3}$ \\ and A. P. Pandirwar ${ }^{5}$ \\ ${ }^{1}$ ICAR-Directorate of Cashew Research, Puttur 574 202, India \\ ${ }^{2}$ ICAR-Indian Institute of Rice Research, Hyderabad 500 030, India \\ ${ }^{3}$ ICAR-Indian Institute of Oil Palm Research, Pedavegi 534 450, India \\ ${ }^{4}$ ICAR-National Research Centre for Banana, Trichy 620 102, India \\ ${ }^{5}$ ICAR-Central Institute for Agricultural Engineering, \\ Bhopal 462 038, India
}

The disposal of oil palm trunk (OPT) congregated from old and senile plantations has been pointed out as one of the major constraints during land clearing process with respect to cost and drudgery involved. Traditionally, the existing practice followed by farmers includes excavation using crawler type excavator (JCB), followed by dragging and dumping in the peripherals of the plantation. Realizing the nutrient status of OPT, their disposal difficulties and to devoid other environmental issues, a chipping bucket attachment was fabricated for the same model excavator to enhance easy fragmentation and rapid in situ decomposition of the congregated OPT. The chipping bucket method effectively minimized the cost of land clearance by $24 \%$ compared to the existing practice followed by farmers. To estimate the cost of clearance per unit palm, an equation was derived using palm height and chipping time. The equation obtained was validated for significant $R^{2}$ value $(0.923)$. The equation thus derived would help farmers as well as excavator operators in estimating land clearance cost for the standing oil palm plantations. This machine effectively reduced the trunk disposal cost from 1.54 to 1 time compared to the existing land clearance method.

Keywords: Oil palm trunk, chipping bucket, cost effective, fragmentation, land clearance.

OIL palm plantations provide stable economic yields up to 25-30 years of age. For optimization of farmers' income, replanting of the plantation is highly essential. The major constraints encountered during replanting of unproductive and senile orchards include land clearance as well as uprooting of the oil palm trunks (OPTs) which also have the problem of disposal. The oil palm tree produces large amounts of biomass once in a lifespan (trunk, root bole) or on regular basis (fronds, male inflorescence) available round the year and all of this goes as disposable waste $^{1}$. The OPT alone contributes to a major portion of about $48-50 \%$ on wet weight basis ${ }^{2}$. Because of its bulky nature, some farmers are adapting the practice of in situ

*For correspondence. (e-mail: pppreethifruitscience@gmail.com) burning which leads to loss of nutrient and soil biodiversity, global warming, acid rain and other environmental issues. To eliminate crop residue burning most countries are working to adapt sustainable methods with efficient resource conservation technologies for conservation and recycling of soil carbon. Felling, dragging and dumping (FDD) are also common existing practices concurrent to land clearing process.

Alternately OPTs are identified as a potential nutrient source, where they are allowed to decompose in situ trenches or in periphery of plantations for seasoning of soil by adding organic matter ${ }^{3-5}$. This is another common practice adopted by farmers besides its non-agricultural utility $^{6}$. This process demands larger space and acts as an active breeding site for pest, disease inoculum and rodents. Also, the biological decomposition of OPTs takes longer (approximately 2-3 years) and causes environmental issues, viz. biological oxygen demand (BOD) and global warming through release of undesirable green house gases into the atmosphere ${ }^{7}$.

Scanning these horizons, for easy fragmentation of OPT and to enhance rapid in situ decomposition, a chipping bucket was fabricated for chain-type JCB excavator which is commonly used by Indian farmers for various farm operations.

The experiment was conducted at ICAR-Indian Institute of Oil Palm Research (IIOPR), Pedavegi (Andhra Pradesh, India). Ten-year-old oil palm plantations with varying plant heights ranging from $1.9 \mathrm{~m}$ to $10.7 \mathrm{~m}$ were used as biological material. The observations, i.e. palm height, palm girth at base, middle and crown base, palm felling time, weight of fragments, number of strokes and total chipping time were recorded.

The chipping bucket used in this experiment was designed and fabricated by IIOPR.

The solid modelling of oil palm chipping bucket assembly was constructed through CAD software with three stages (Figure 1): (a) part modelling, (b) assembly modelling and (c) creation of design drawings. In part modelling, each and every part was developed according to design measurements with various software commands. In assembly modelling, each and every part was assembled together with assembly constraints. The third stage, i.e. creation of design drawings for all parts and assembly, incorporated all the necessary dimensions and notes to manufacture the oil palm chipping bucket assembly.

During manufacture, initially, the unbent bucket main plate was cut into a trapezoidal shape with a gas cutting machine and bent with a hydraulic rolling press into the specified shape according to the design drawing. All the edges were then ground. Then, the bucket side plates were cut according to the designed template and all edges were ground. These side plates were welded to the bucket main plate on both sides. The chipping bucket blade was cut according to the specified shape with a gas cutting machine and grinding machine, and then welded to the 

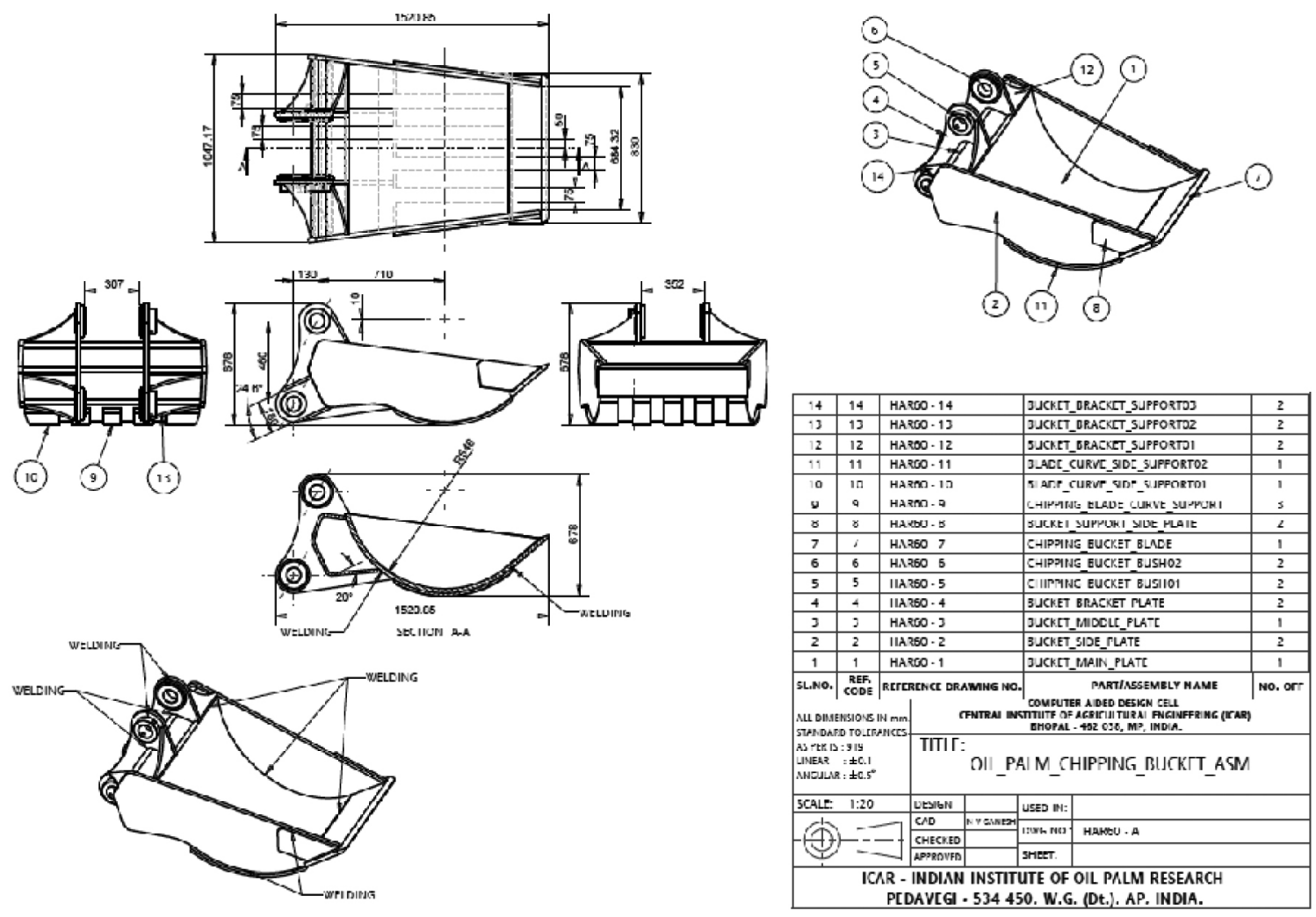

Figure 1. Illustration and dimensions of different parts of chipping bucket.

main plate and side plates. The unbent size of the bucket middle plate was cut according to size; three bends were formed according to shape and welded with the main plate and side plates. Then, the bucket bracket plates were cut according to template with bush holes and then welded to the middle plate and main plate. The chipping bucket bush 01 and 02 were fitted at the specified holes of the bracket plate and welded at both sides. The bucket support side plates were cut according to shape and welded to the side plates at both sides. The chipping blade curve supports, blade curve side support 01 and 02 were cut according to size and bent as the bucket main plate and then welded to the bucket main plate to strengthen the bucket assembly. The bucket bracket support 01 , 02 and 03 were cut according to shape and welded at specified places to improve the strength of the bucket assembly. The excess burrs on the entire bucket assembly were removed with a grinding machine. The material of the chipping bucket blade was stainless steel and all other parts were mild steel.

The application of this bucket is to make small pieces of chips of fallen or dead palms, for fast decomposing. The function of the oil palm chipping bucket is to apply the self weight stroke with gravitational force on the peripheral surface of the oil palm stem and make a cut using the sharp end of the bucket blade. It is then released back. This operation repeatedly applies strokes, with little distance between the blade and the periphery of the stem, to form pieces of chips.

The novelty of the chipping bucket is as follows: Size reduction for faster decomposition: The chipping bucket reduces the huge OPT into chips of desirable size and enhances the rate of decomposition.

Soil fertility: The decomposed OPT chips nourish the soil with essential elements and improve the textural and biological properties of soil.

Mulch material: Chips of the OPT act as mulch and eventually mitigate soil erosion and conserve soil moisture.

Incongruous breeding site for pests: Unlike whole OPT dumping, chopping improves aeration and light penetration, which cause an uncongenial habitat and breeding site for insects, disease inoculum and rodents.

The chipping bucket attached to the crawler type excavator was validated for its performance with 115 palms of different heights. To assess the significance of the variables related to palm characteristics, which influence the chipping time of the palm, a regression equation was applied using simple linear regression (SLR) analysis. The model of SLR analysis is said to operate the relationship of the dependent variable $(Y)$ to independent variable $\left(X_{1}\right)$ which can be expressed as

$$
Y=b_{0}+b_{1} X_{1}+e
$$




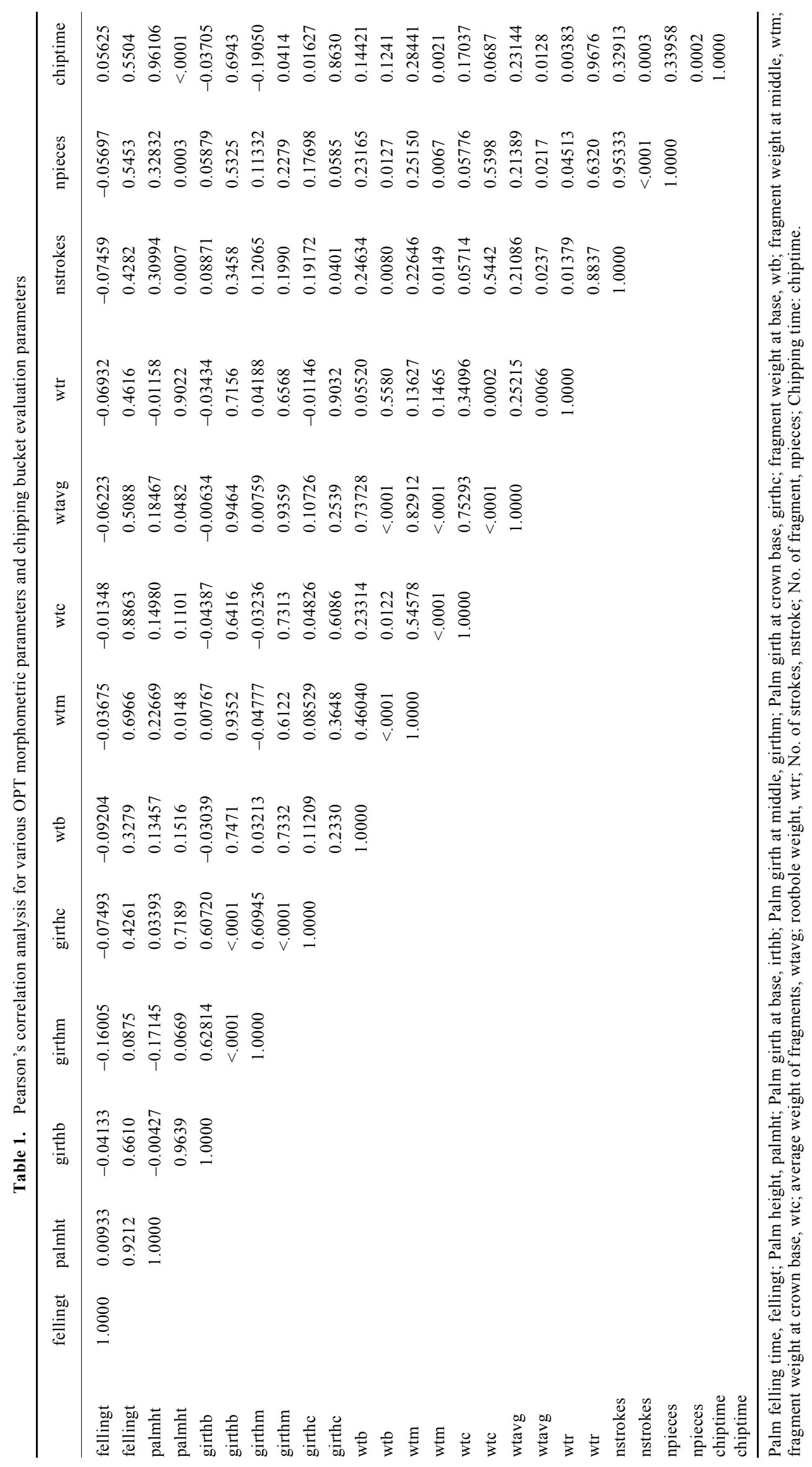



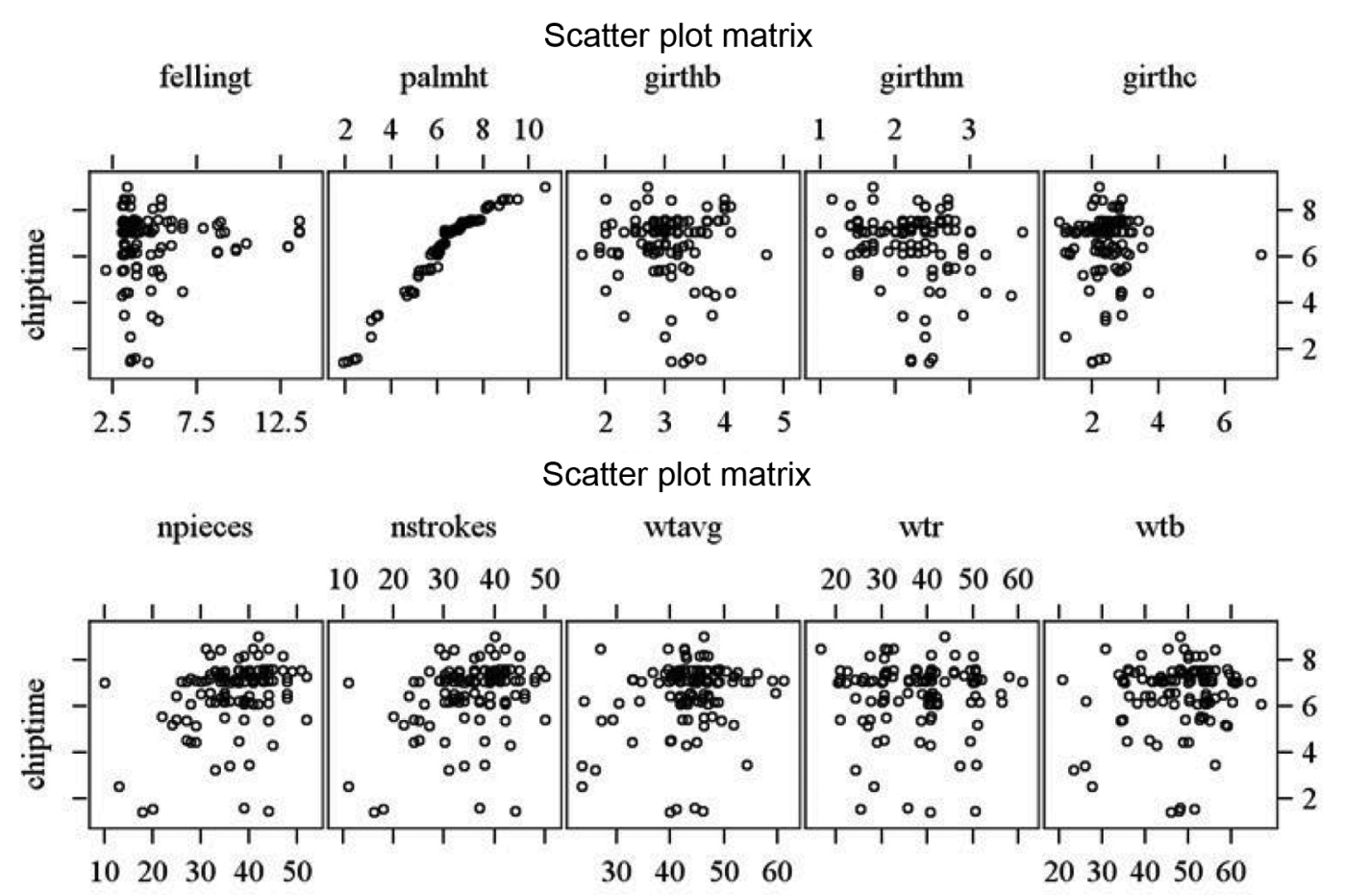

Figure 2. Scatter plot matrix for oil palm trunk morphometric parameters and chipping bucket evaluation parameters. Palm felling time, fellingt; Palm height, palmht; Palm girth at base, irthb; Palm girth at middle, girthm; Palm girth at crown base, girthc; fragment weight at base, wtb; fragment weight at middle, wtm; fragment weight at crown base, wtc; average weight of fragments, wtavg; rootbole weight, wtr; No. of strokes, nstroke; No. of fragment, npieces; Chipping time, chiptime.

Table 2. Components of the prediction equation of the chipping time of the oil palm as a function of variable (palm height)

\begin{tabular}{lccccccc}
\hline Variables & Parameter estimate & Standard error & $t$ value & $\operatorname{Pr}>|t|$ & $R^{2}$ & Adjusted $R^{2}$ & CV (\%) \\
\hline Intercept (constant) & 0.09747 & 0.17839 & 0.55 & 0.5859 & 0.9236 & 0.9230 & 6.30 \\
Palm height (coefficient) & 1.00710 & 0.02724 & 36.97 & $<0.0001$ & & & \\
\hline
\end{tabular}

Table 3. Prediction model for the palm chipping time as a function of the palm height

\begin{tabular}{lcc}
\hline Estimated $(Y)^{*}$ & Simple linear regression equation*** & $R^{2}$ \\
\hline $\mathrm{CT}$ & $Y=0.0975+1.0071 \mathrm{PH}$ & 0.923 \\
\hline
\end{tabular}

${ }^{\#}$ Chipping time estimate $(Y)$; CT, Chipping time; PH, Palm height; $* * * P<0.001$.

where $Y$ is the sum of chipping time determined by the palm height, $b_{0}$ the inherent constant in the model, $b_{1}$ model regression coefficient and $e$ is the error associated with the observation which is assumed to be normal and independently distributed.

To explain the relationship of the variable that correlated with the chipping time in the regression analysis, Pearson's correlation was used.

The association between palm characteristics (height, girth, age, etc.) is crucial for estimating the chipping time which can be evaluated by means of correlation analysis and scatter plot matrix. This can determine which variables influence, to a greater or lesser degree. This gives the significant high correlation between the chipping time (CT) and palm height (PH) than other estimated parameters (Table 1 and Figure 2). Thus owing to ease of measurement and its non-destructive character, the $\mathrm{PH}$ was tested as a component of the equation to predict the CT (Table 2 and Figure 3).

The SLR model was fit taking PH as the independent variable. The SLR model was significant and positive for $\mathrm{PH}$ with low coefficient of variation $(6.30 \%)$ and high determination coefficient $(0.924)$. These results provide an easy measurable indicator suggesting the possibility of advance planning of the cost of oil palm felling, followed by chipping with considerable reliability. The time taken for fragmentation of whole OPT depends on $\mathrm{PH}$ and size of chip fragmented. The chipping time increased with increasing $\mathrm{PH}$, invariable to chip size. For fragments of 20-25 cm size, the recorded CT was scatter plotted 
(a)
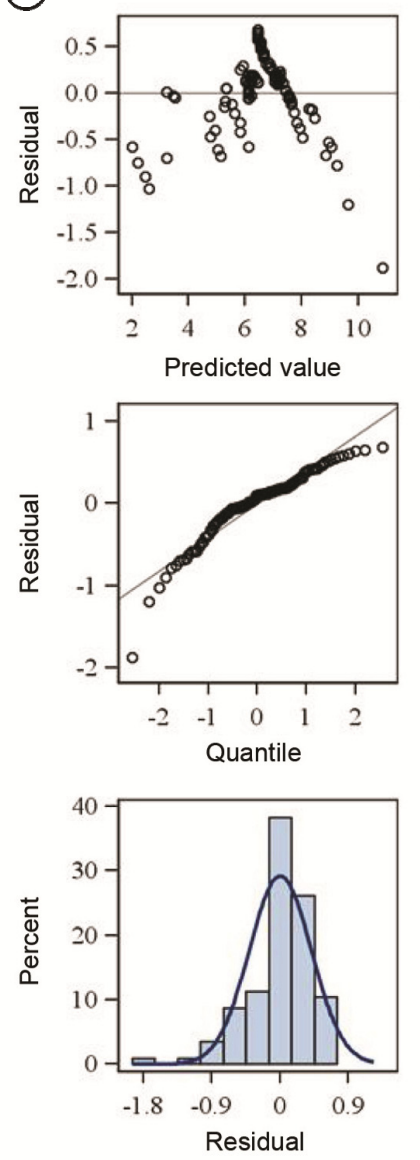

Fit diagnostics for chipping time
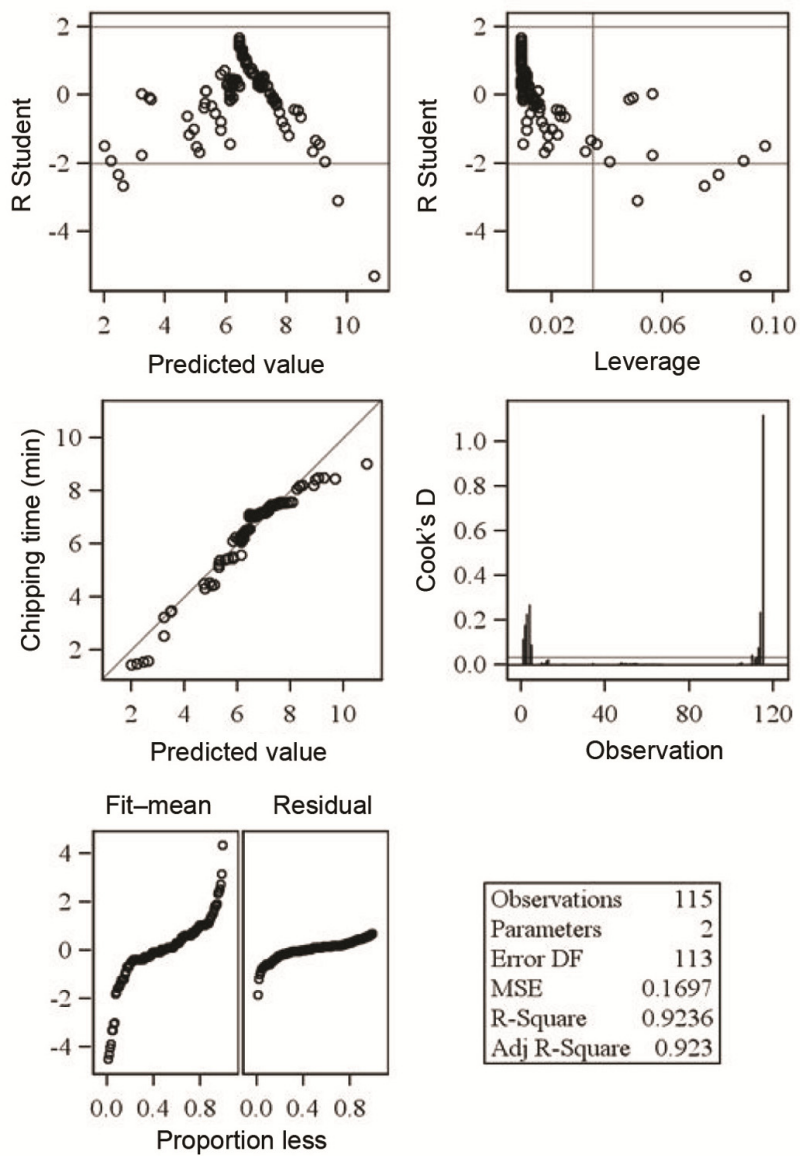

\begin{tabular}{|lr|}
\hline Observations & 115 \\
Parameters & 2 \\
Error DF & 113 \\
MSE & 0.1697 \\
R-Square & 0.9236 \\
Adj R-Square & 0.923 \\
\hline
\end{tabular}

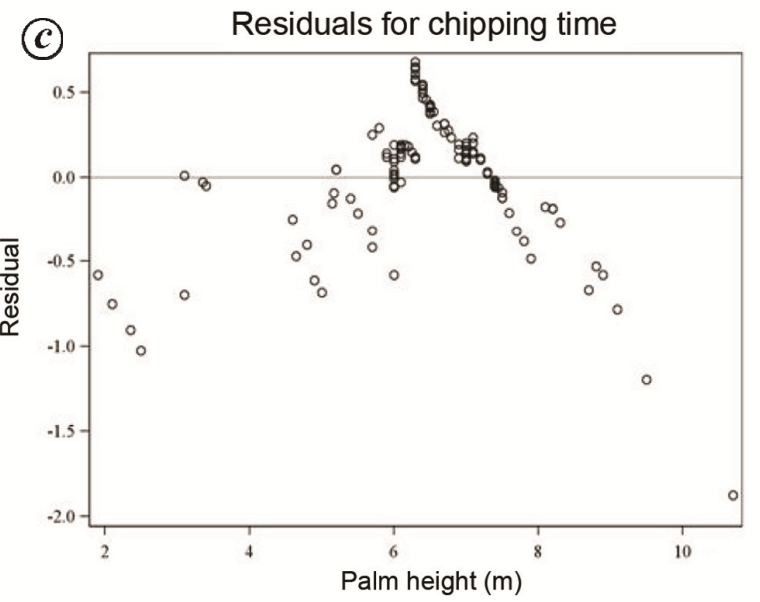

Figure 3. $\boldsymbol{a}$, Fit diagnostics for observations recorded in chipping bucket evaluation; $\boldsymbol{b}$, prediction model between chipping time and palm height; $\boldsymbol{c}$, other variables.

against PH for obtaining the $R^{2}$ value (Table 3 and Figure 4).

Estimated chipping time (min)

$=(1.0071 \times$ average palm height in $\mathrm{m}+0.0975)$

$\times$ Total no. of palms to be uprooted.

In the FDD practice, the cost depends on the land coverage to be cleared, since uprooted palms are individually

Cost of land clearence $=\frac{\text { Estimated chipping time }(\mathrm{min})}{60}$

$\times$ Rent of chain type JCB per $h$. 
Table 4. Cost analysis of existing practice (FDD) and chipping bucket method in the process of oil palm plantation clearance

\begin{tabular}{|c|c|c|}
\hline & Particulars of FDD practice & Chipping bucket method (oil palm as mono crop) \\
\hline Practice of land clearance & Felling and dragging of oil palm trunks & Felling and chopping of oil palm trunks \\
\hline Machineries required & $\begin{array}{l}2 \text { excavators (JCBs) and } 1 \text { crawler type excavator (JCB) } \\
\text { (Three machines worked together to fell and drag the trunks) }\end{array}$ & 1 crawler type excavator $(\mathrm{JCB})$ \\
\hline Rent of JCB per h (INR) & $\begin{array}{l}2000 / \mathrm{h}(1000 / \mathrm{JCB} / \mathrm{h}) 1500 / \text { chain type } / \mathrm{h} \\
\text { Total cost per } \mathrm{h}=\text { Rs } 3500\end{array}$ & $\begin{array}{l}\text { 1875/h (Hitachi } 200) \\
\text { Total cost per } h=\text { Rs } 1875\end{array}$ \\
\hline $\begin{array}{l}\text { Average time of disposal } \\
\text { (in working hours) }\end{array}$ & $\begin{array}{ll}\text { For single palm } & 7.32 \mathrm{~min} \\
\text { For } 115 \text { palms } & 14 \mathrm{~h}\end{array}$ & $\begin{array}{ll}\text { For single palm } & 8.87 \mathrm{~min} \\
\text { For } 115 \text { palms } & 17 \mathrm{~h}\end{array}$ \\
\hline Total cost of felling (INR) & $\begin{array}{lc}\text { For single palm } & 426 \\
\text { For } 115 \text { palms } & 49,000\end{array}$ & $\begin{array}{l}\text { For single palm } \\
\text { For } 115 \text { palms }\end{array}$ \\
\hline Benefit cost ratio $(\mathrm{B}: \mathrm{C})$ & $\begin{array}{l}\text { The benefit cost ratio of chipping bucket method } \\
\text { compared with FDD practice }\end{array}$ & $1: 1.54$ \\
\hline Remarks & $\begin{array}{l}\text { Only felling and staking. After felling palms/trunks are } \\
\text { burnt causing environmental hazard or staked which is } \\
\text { emerging as potential threat (for major and minor pests) } \\
\text { as these are harbouring centre }\end{array}$ & $\begin{array}{l}\text { Enhances rapid decomposition } \\
\text { Improves soil texture and microbial diversity }\end{array}$ \\
\hline
\end{tabular}

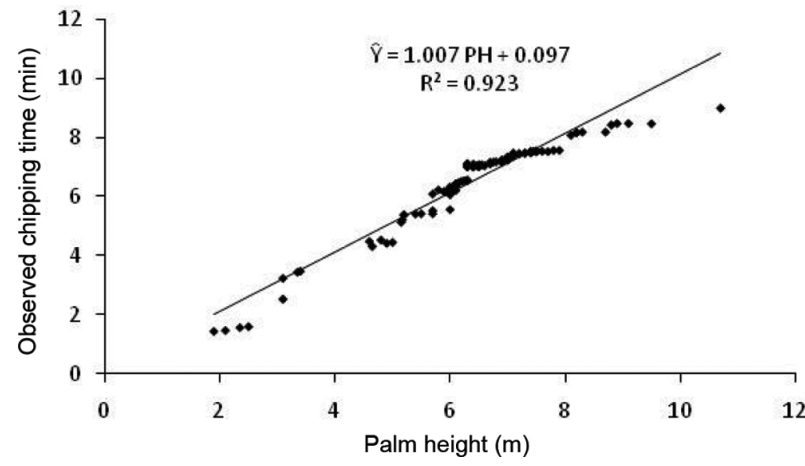

Figure 4. Validation model for estimation of oil palm trunk chipping time in standing plantation.

dragged and dumped in the plantation periphery. Two JCBs and one crawler type JCB were needed to work together for $14 \mathrm{~h}$ to clear 1 ha of land. However, in chipping bucket method, only one crawler type JCB was sufficient to chop and incorporate OPTs in the field in si$t u$. Thus the dragging process was skipped and eventually the cost was minimized up to $24 \%$ compared to FDD practice. The cost effectiveness of this machine was calculated by dividing the investment cost of chipping bucket and FDD method, and it gave a cost benefit ratio of $1: 1.54$. Hence, this method was found to be a feasible approach for land clearance while replanting oil palm plantations (Table 4).

The potential nutrient pool, OPTs are allowed to decompose in plantation sites to improve soil health ${ }^{4,8}$. OPT pulverization for rapid decomposition has not been documented so far. Pulverization of OPT is a potential technique in reducing breeding of rhinoceros beetle, ganoderma and rodents ${ }^{9}$.

The chipping bucket was designed for efficient utilization of OPTs in improving the soil microbial diversity, texture and fertility by aiding their rapid decomposition. The cost of land clearance in the existing mechanical method of felling, dragging and dumping is very high. However, the same work with the developed chipping bucket attachment is cost-effective. The developed method also makes the in situ fragmentation much easier in lesser time periods. Moreover, moving heavy vehicles on chopped oil palm trunk pieces results in compaction and expels moisture from the chopped OPTs, thus enhancing their drying and decomposition rates. Hence, chipping bucket provides a reliable and cost effective alternative to the existing cumbersome FDD method without any additional investment. This also adds nutrient to the soil substrate, prevents soil erosion and leaching of soil nutrients from plantation sites.

1. Abdullah, N. and Sulaiman, F., The oil palm wastes in Malaysia. In Biomass Now - Sustainable Growth and Use (ed Matovic, M. D.), IntechOpen, Malaysia, 2003, pp. 75-100; http://dx.doi.org/10.5772/ 55302.

2. Basiron, Y. and Weng, C. K., The oil palm and its sustainability. J. Oil Palm Res., 2004, 16, 1-10.

3. Chan, K. W., Watson, I. and Lim, K. C., Use of oil palm waste material for increased production. Planter, 1981, 57(658), 14-37.

4. Kee, K. K., Nutrient reserves and recycling from oil palm trunks at replanting. Changes, 2004, 32(5.4), 27-28.

5. Sulaiman, F., Abdullah, N., Gerhauser, H. and Shariff, A., An outlook of Malaysian energy, oil palm industry and its utilization of wastes as useful resources. Biomass Bioenergy, 2011, 35, 37753786; https://doi.org/10.1016/j.biombioe.2011.06.018.

6. Lim, K. C. and Zaharah, A. R., Decomposition and N\&K release by oil palm empty fruit bunches applied under mature palms. J. Oil Palm Res., 2000, 12, 55-62.

7. Shuit, S. H., Tan, K. T., Lee, K. T. and Kamaruddin, A. H., Oil palm biomass as a sustainable energy source: a Malaysian case study. Energy, 2009, 34, 1225-1235; https://doi.org/10.1016/j.energy. 2009.05.008.

8. Haron, K., Zakaria, Z. Z. and Anderson, J. M., Nutrient cycling in an oil palm plantation: the effects of residue management practices during replanting on dry matter and nutrient uptake of young palms. J. Oil Palm Res., 2000, 29(2), 29-37.

9. Ooi, L. H. and Heriansyah, H., Palm pulverisation in sustainable oil palm replanting. Plant Prod. Sci., 2005, 8, 345-348; https://doi.org/ $10.1626 /$ pps.8.345.

Received 3 October 2018; revised accepted 4 December 2018

doi: $10.18520 / \mathrm{cs} / \mathrm{v} 116 / \mathrm{i} 6 / 1003-1008$ 